\title{
CONFLICTING CONCEPTIONS OF PLACE BETWEEN CIVIL SOCIETY AND COUNCIL ACTORS INVOLVED IN LOCAL-LEVEL FOOD POLICY DEVELOPMENT: THE CASES OF DEVON AND BATH, UK
}

\author{
Daphne Page
}

\section{INTRODUCTION}

In the United Kingdom, the number of local-level food policies is on the rise (Moragues-Faus \& Morgan, 20 I5; Santo \& Moragues-Faus, 2019). Unlike at the national level, where food policies are at risk of being watered down or scrapped as a result of Brexit, local authorities have scope to implement changes quickly, with an eye to resilience and sustainability (Lang et al., 20l8). These local-level policies are being developed within a national context of devolution, with regional and municipal councils being required to take greater control over their local policies and finances (Morgan, 20I4). This activity is coupled with significant cuts to the public sector. Increased awareness of global-level issues such as climate change, public health crises and non-communicable diseases (NCDs) related to lifestyle, and damage to the environment, has resulted in social mobilisation demanding change and a desire for associated policy actions (Goodman et al., 20 I2).

Integrating sustainable values and practices into the local food system is increasingly being viewed as a necessary way to confront the unsustainability of the global industrial food system (Mason \& Lang, 20 I7). Marsden argues that global pressures (climate change, population growth, the "nutrition transition") are pushing 'down' on the global food system, while those concerned with sustainability are pushing 'up' from the grassroots to incite a system shift (20I3, p. 125). This paper contributes to this dialogue through an examination of two case studies of local areas in England (UK), Bath and Northeast Somerset (BNES) and Devon. Both of these regions have developed local-level food policies through partnerships with the local authority (LA) and with civil society (CS) groups. The two case studies examine the differing views of these two groups of actors on how local-level food production can contribute to sustainability, with addressing both urban and rural production systems being a particular challenge.

\section{BACKGROUND}

The creation of "alternative food systems," such as local short-food supply chains, has become more popular over the last decade (Goodman et al., 20 I2). Food production has been referred to as "the low hanging fruit of transition" (Hinrichs, 20 I4, p. I46), as food connects and overlaps with so many aspects of daily life and policy. This allows actions taken within the food system to have multiple and overlapping impacts for a municipality. For example, studies of urban agriculture (UA) have shown that community gardens can offer improved community cohesion through increased pride in place, reduced crime and improved mental health, as well as increased fruit and vegetable consumption (Mougeot, 2006; Pollans \& Roberts, 20 I4). Likewise, improved access to local markets for producers and the promotion of agri-tourism can support the rural economy. 


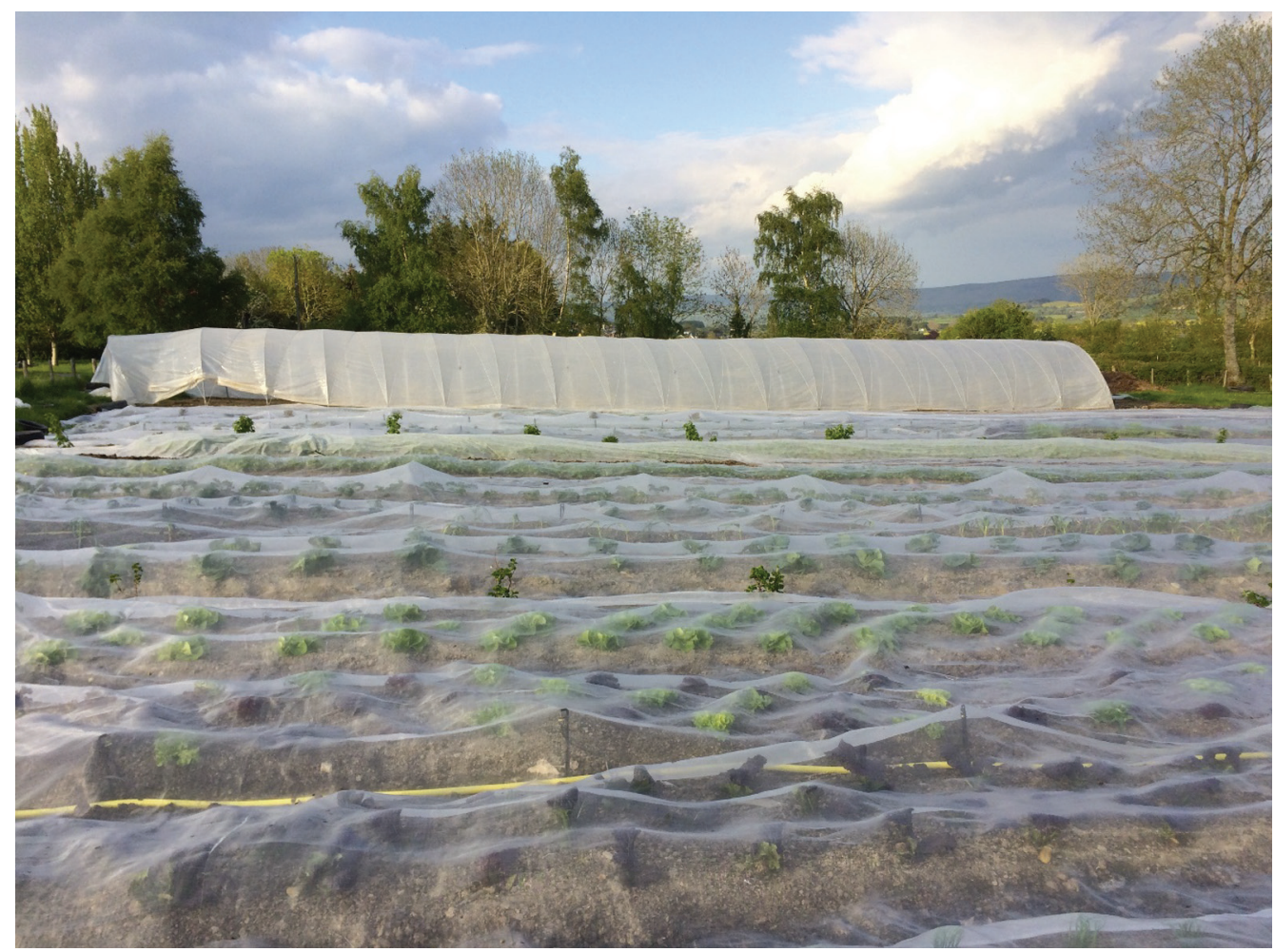

Figure I. Small-scale market garden as an example of a sustainable vegetable production initiative in rural England. Source: Author.

It is within this context that civil society (CS) and local authority (LA, or 'council', henceforth) actors are coming together in towns, cities and counties across the United Kingdom to create bespoke local food policies to respond to local sustainability objectives.

The meaning of the term 'local' has been contested in the context of food. Academics suggest caution in asserting or assuming that locally produced food is indeed more sustainable than the alternative, and have dubbed this phenomenon "the local trap" (Marsden \& Franklin, 2013, p. 637). This issue has led some academics to suggest a cautionary approach when making sweeping assertions about the benefits of relocalisation of the food system. DuPuis and Goodman (2005) note the trend - that in research on relocalisation and alternative food networks (AFNs), "the global becomes the universal logic of capitalism and the local the point of resistance to this global logic" (p. 359).They argue that "unreflexive localism" could be a potential outcome of a "romantic anti-politics" of the local food system and could nurture the "ideological foundations for reactionary politics and nativist sentiment" (p. 360).

\section{"PLACE AND PLACENESSESS"}

Many scholars, as well as writers such as Henry David Thoreau in Walden and farmer-philosopher Wendell Berry, have argued that the global industrialised food system has caused a sense of disconnection or "placelessness" (DuPuis \& Goodman, 2005, p. 360) that results from no longer knowing where our food comes from or how it is grown. There are both emotional and practical implications arising from this distancing of food from its production. 
Previous issues of Scope have examined and defined the concept of a sense of place through both theoretical and practical lenses (see Aimers and Ross, respectively, in Scope: Health and Wellbeing, 2, November 2017). The development of UK food policy has been examined by scholars as a 'place-based' innovation, linking to food security, partnerships and governance (Coulson \& Sonnino, 2019; Moragues-Faus \& Sonnino, 2019). To date, research on UK food policy initiatives has had a predominantly urban focus, adding an unevenness to the examination of place in relation to these policy developments (Coulson \& Sonnino, 2019).

While a sense of place is crucial to writing local-level policy that reflects the context of its municipality, the perspectives of those involved in policy development can diverge on fundamental aspects of how they understand 'place' in realtion to the landscape(s) of local food production, and people's relationship to it. These differing views represent tensions in the policy-making process, but are often unresolved as a result of the power relationships within these partnership groups.

\section{METHODOLOGY}

Research on the two case studies presented here was conducted between 2014 and 2019 as part of a doctoral dissertation on local-level food policy development in the UK's Sustainable Food Cities Network. This research received ethical approval from the Research Ethics Committee at City, University of London. The cases were selected based on the criteria of having local-level food policy initiatives developed through partnerships with civil society and council actors that were current at the time the research was begun (20 I4).

The cases of BNES and Devon illustrate two contrasting partnership group structures, along with the different narratives that emerged within their respective groups and policies relating to food production, sustainability and 'place.' Devon's partnership structure is characterised as a primarily CS-led effort, supported and overseen by the local council and structured according to council priorities. In contrast, the BNES food policy initiative was initiated and led by the LA, with the participation of some CS actors by invitation; as a result, the objectives and general approach were set early in the process by the council. In this research, 'local' - as the term applied to the food policies created by the Devon Food Group and the BNES council - was defined in its spatial sense and based on the political boundaries of each council. However, describing what constitutes local food production, and how it is or isn't sustainable, is less easily drawn out or defined.

This study took the form of qualitative interviews with both CS and LA actors involved in local-level food policy development: five actors from Bath and Northeast Somerset were interviewed (three LA actors and two CS actors), and six from Devon (one LA actor and five CS actors). The interviews focused on the beliefs of the actors relating to local-level food production and how it can foster sustainability objectives.

In addition to the interviews, relevant policy documents (as an output of the collaborative policy process) were analysed qualitatively, with attention to content relating to food production and sustainability. An examination of Feeding Devon's Future (Devon Food Strategy and Action Plan 2013-2016) and the BNES Local Food Strategy (20/4-2017) (Bath and Northeast Somerset Council, 2014) showed how the views and priorities of actors were represented in these documents. This in turn offered insights into the partnership dynamics between CS and LA actors and how this affected the content of the respective food policies.

\section{THE CASES}

The cases of BNES and Devon offered two models of policy collaboration between civil society and local council actors. These differed in the balance of civil society and council participation in the respective steering groups, as well as the extent to which the council set priorities to guide strategy content. These partnerships were based on a need to merge resources in a context of austerity - resources such as knowledge, networks, capacity, funding and authority (including the ability to make policy change at the municipal level). 


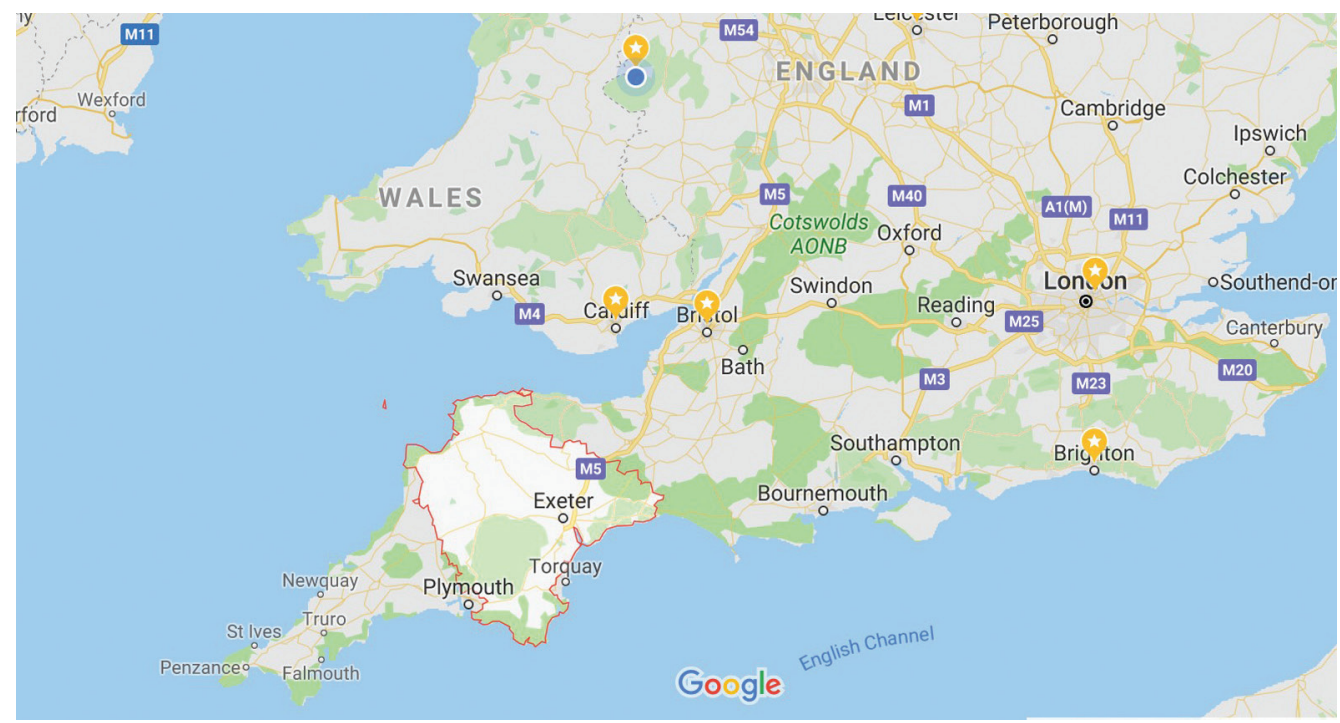

Figure 2. Map showing the County of Devon in the United Kingdom to illustrate the case study area.

Source: Google Maps, 2019.

\section{Case Study I: Devon}

Devon is a county in England's South West. It is characterised by extensive rural agricultural land use that is dedicated primarily to livestock grazing and arable production of grains as livestock feed, with vegetable and fruit production as a small proportion of the sector (Devon Strategic Partnership, 20 I4).

The make-up of the coalition that created Devon's food 'strategy' could be defined as "[a] hybrid of civil society organizations and government with a conduit to decision makers through municipal council, and with municipal financing, political champions, and supportive staff" (MacRae \& Donahue, 20I3, p. 9). While proposed by a member of civil society and a mostly CS steering group, the main objectives and oversight of the food policy were provided by the local county council. One CS actor described the process as being "quite top-down," adding that "it ended up being quite high level, Devon-wide." Although CS actors agreed that there was a need for both urban and rural agriculture to balance a policy document, a focus on the rural economy was the council's main objective in the policy. The steering group was required to maintain this emphasis to ensure continued LA support.

Despite this constraint, CS actors used Feeding Devon's Future as a means of promoting their message, directing recommendations to the council and framing issues in urgent terms, with particular attention to the environment, food poverty and food security. Questions relating to the environment and the economy remained focused on the rural, and only through the social 'pillar' was any content relating to urban agriculture considered. UA was offered as a means of addressing issues of poor health, lack of skills, and access to food to address food poverty - all in areas of greater (urban) population density. The issue that cut across all three three 'pillars' was a lack of knowledge of food associated with the global industrial food system. This included production in general and sustainable production methods in particular (thus connecting to farmers).

Devon's food strategy is based on binary narratives of past versus present and local versus imported, functioning as proxies for 'sustainable' and 'unsustainable.'The notion of an ideal period in the past which was more sustainable than the present is deeply embedded throughout the document. Within this emphasis are nested a number of related narratives, such as knowledge versus ignorance, connection versus disconnection and nature versus development. The strategy refers to "the ignorance of younger people" (p. 13), the fractured relationship with food 
of "recent generations" (p. 13) and the present being "a time of public ignorance of the food-cycle" (p. 12). These sentiments were reflected in the interviews with civil society actors who drafted the document. In the strategy, Devon's traditional ability to provide much of its staple food items has it referred to as a "land of milk and honey" (p. 8). It harkens back to a supposed time when Devon's citizens lived lives connected to the land and contrasts this with the present: "Long gone are the days when most people in Devon grew, prepared, cooked and ate their own produce, with any leftovers being passed on to pigs or poultry" (p. 13). This highly romanticised view of the thriving, sustainable, healthy rural Devon of the past is held up as something to aspire to in the present.

With Devon County Council as the implied main audience for Feeding Devon's Future, there is an assumption that it has the power to make changes to correct these modern-day ills that are besetting the county. Implicit in this is that by presenting such a stark portrait of the county's rural circumstances, a compelling appeal might be made to the council based on its own stated priority areas. As a result of the council's rural emphasis, once the document was finalised, the CS actors involved in the steering committee detached themselves from council oversight to launch the Exeter Food Strategy. This CS initiative was founded on the basis that it represented the needs of one of the most populated urban areas of Devon - issues such as food poverty, lack of knowledge, training and influencing procurement.

\section{Case Study 2: Bath and Northeast Somerset (BNES)}

Bath and Northeast Somerset is a unitary authority in England's South West. The area has a significant green belt, including historic agricultural land, and the main city, Bath, has a market tradition. The Bath and Northeast Somerset Local Food Strategy (20 I 4-20 I7) was a council-led initiative. Davies identifies the BNES Sustainable Food Partnership as one of several "[f]ood partnerships housed within the public sector" across the UK (2017, p. 5). The effort was launched by the BNES Environmental Sustainability Partnership (ESP) as a joint effort by Bath Council's sustainability team and the BNES Health and Wellbeing Board (HWBB). A steering group was convened by these council groups and CS actors were invited to participate. However, the council held ownership of the process and the output.

Within the policy document, references to food production identify a place for both urban and rural growing. Where farming is mentioned, it is typically referred to as "farming businesses," reflecting the view that rural agriculture is largely seen in economic terms by the council. The rare mentions of farming methods include the suggestion that these need to change in order to be "more sustainable," implying environmental concerns. However, the document's attention to rural production is minor compared with its emphasis on "community growing," implying an urban focus. In the BNES partnership, council and CS actors expressed concern over people being disconnected from food production as a result of imports, resulting in a skewed understanding of access and seasonality. Reduced knowledge of food growing and cooking skills in particular were linked to poorer health. These concerns drive the urban growing and training emphasis seen in the policy, and the provision of growing space through community gardens and allotments.

Throughout the interviews, council actors referred in passing to rural food production in only two contexts. The first was in relation to farmers and landowners taking part in the consultation process (and how few did so), and the second referred to the need to develop markets for local producers. CS participants expressed an awareness of this narrow approach to local food production by the council actors involved. One CS actor recalled that no clear distinction was made between urban and rural growing in the strategy development discussions. Another held more critical views about how food production had been used as a tool for the strategy: "[T] here's been an emphasis and even a reliance on community gardening to act as the local food component ... I haven't seen that the council is really engaging with agriculture."'The CS actors interviewed felt that rural agriculture wasn't well understood by council actors and that this compromised the strength of the policy for BNES as a whole, as a rural, peri-urban and urban food producer. For them, this left the impression that urban agriculture and its associated social outcomes were the main priorities for the council. 


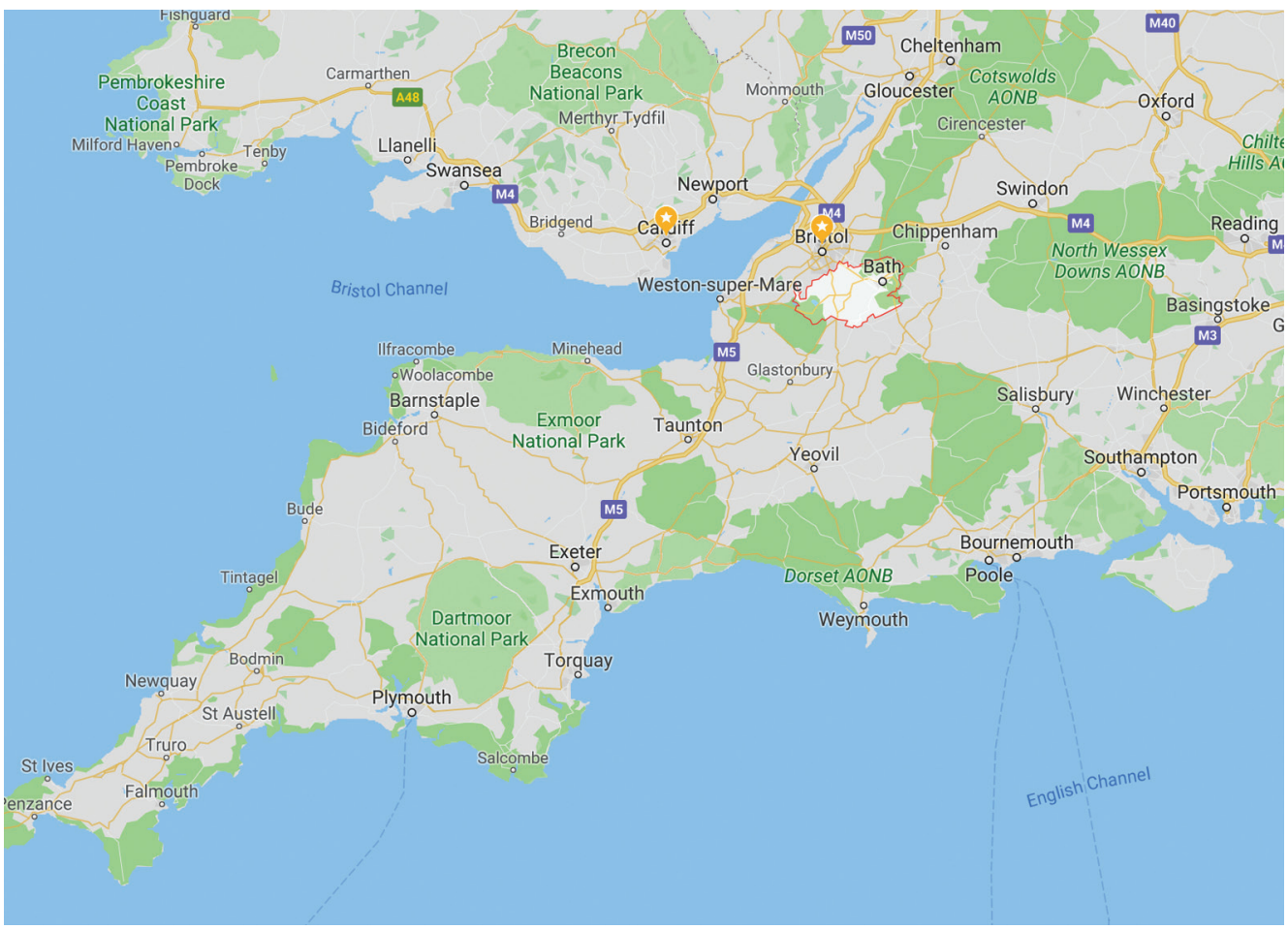

Figure 3. Map showing the County of Bath and Northeast Somerset in the United Kingdom to illustrate the case study area. Source: Google Maps, 2019.

\section{FINDINGS}

Qualitative analysis of the interviews revealed some common themes across participant narratives. This research project found that, in these two cases, both civil society and council actors seek to use local-level food policy as a means of fighting back against a sense of 'placelessness' and disconnection from food production. In the interviews, participants spoke of what they understood 'local' food production to be, as well as how it was linked to sustainability in the standard three-pillar model of society/health, environment and economy. The territorially embedded nature of food production necessarily prompts reflections on the geographical origins and characteristics of food and the human connections to it. Likewise, in relation to local food production 'sustainability' prompts reflection on the links between global-level systems and how they impact on and are impacted by local-level actions. As one interview participant from Devon noted, "everywhere is local to someone - but it doesn't actually mean that it's in any way sustainable in an environmental or social sense of the word."

As food production is necessarily bound to a physical place through its origins in or on the land (or sea), this highlights the reality that our relationship to food is highly personal, especially as it relates to what we as individuals view as local. During the course of this project, I observed that despite their many shared aims, actors struggled to agree on a common understanding of 'place,' particularly in relation to food production in urban and rural contexts. Actors spoke of where production took place in their locality (typically expressed as 'rural' or 'urban'), what types of production were taking place, how it contributed to sustainability objectives, and who was intended to participate in projects to achieve their aims. When these interview themes were compared to the content of their respective food policy documents, the dominant voice(s) within the partnership groups (along with their objectives and concerns) became apparent, with others lacking representation. 


\section{DISCUSSION}

Despite joining together in partnership (for sharing resources, including but not limited to, funds, human resources, skills and networks), civil society and council actors presented an 'us versus them' mentality in interviews. The two cases varied in the structure of their partnership groups, as well as the priority food production areas identified in their policy documents, being urban for BNES and rural for Devon. In both cases, CS actors demonstrated frustration with the council's lack of practical knowledge about food production and agriculture in their municipalities, whether rural (BNES) or urban (Devon), suggesting a lack of knowledge beyond the council's priority areas. At the core of the CS-LA divide is a lack of common understanding of the food production 'landscape.'This results in disagreement on priority action areas for food production, despite shared beliefs in the reality of disconnection as a spatial, temporal and cognitive issue facing citizens.

In both cases, the council held a position of power over the policy process. This situation is typical of a local-level food policy environment, which Coulson and Sonnino (2019) identify as a "highly unequal, contested and multiscalar governance and policy context" (p. 170). Despite claims to be working in "partnership,' these partnerships were unequal. Although CS actors explained that they wanted to use the opportunity to influence important policies, they felt that the policy aims and core issues had already been determined, leaving little room for meaningful dialogue. Feeling that the council had an incomplete understanding of food production (ironically, noting the theme of 'disconnection' expressed by all), CS actors expressed frustration with what they felt were poorly constructed policies that would fail to meet the diverse circumstances in their areas. However, supporting Hinrich's statement that food is "the low hanging fruit" of local-level policy, this research suggests that council actors were acting strategically in their areas of focus in the face of budgetary constraints and otherwise reduced resources.

Ultimately, the power imbalance evident in these two cases stands at the core of conflicting understandings of space in relation to food production along the rural-urban spectrum. Pre-determined aims and a lack of equal and open dialogue about what comprises the local landscape of food production resulted in tensions within both policy partnerships, as well as a sense of weak policy foundations (largely expressed by CS participants).

\section{CONCLUSION}

In the changing landscape of local-level governance in the UK, scholars Moragues-Faus and Sonnino (2019) have called for "trans-local" links to embed food policy more widely and to "create common imaginaries and a shared vision" (p. I). While this is an essential step to moving local-level food policy (and the SFCN agenda) across the UK, actors at the local level will likely continue to be hindered by the effect of power imbalances on their ability to communicate effectively, even at the lowest levels - within their own local partnership groups. However, building dialogues about 'place' (in relation to the landscape of rural, peri-urban and urban food production) into the policy process could act as a tool to develop a shared vision and a more balanced view of agriculture in food policy at the local level.

Daphne Page (10 0000-0002-0670-7213) is a PhD researcher at the Centre for Food Policy, City, University of London, researching sustainability in local-level food policy-making. As one outcome of her research, she runs a market garden in the town of Bishop's Castle, Shropshire, UK. Daphne would like to acknowledge the support of City University for their generous funding of this research project.

Correspondence to: Daphne Page. Email: daphne.page@city.ac.uk 


\section{REFERENCES}

Aimers, J. (2017). Place and space within community development in Aotearoa New Zealand: A theoretical discussion. Scope: Contemporary Research Topics: Health \& Wellbeing, 2, 8- 15.

Bath and Northeast Somerset Council. (20I4). Bath and Northeast Somerset local food strategy 20 I 4-20 I 7. Retrieved from http:// www.bathnes.gov.uk/sites/default/files/bath_and_north_east_somerset_local_food_strategy_0.pdf

Born, B., \& Purcell, M. (2006). Avoiding the local trap: Scale and food systems in planning research. Journal of Planning Education and Research, 26(2), 195-207. http://doi.org/10.1177/0739456X0629/389

Coulson, H., \& Sonnino, R. (2019). Re-scaling the politics of food: Place-based urban food governance in the UK. Geoforum, 98 , 170-179. http://doi.org/10.1016/j.geoforum.2018.11.010

Davies, S. (2017). Food partnership structures: Stories from sustainable food cities. Retrieved from http://sustainablefoodcities.org/ Portals/4/Documents/Governance\%20and\%20Structures\%20Guide\%20FinalAM.pdf

Devon Strategic Partnership. (n.d.). Devon food strategy. Retrieved from https://new.devon.gov.uk/devonsp/devon-food-strategy

Devon Strategic Partnership. (2014). Feeding Devon's future (Devon Food Strategy and Action Plan 20I3-20।6). Retrieved from https://democracy.devon.gov.uk/Data/Cabinet/20 I 4 1008/Agenda/supplementary\%20information-CS- | 4-36.pdf

Duell, R. (2013). Is 'local food' sustainable? Localism, social justice, equity and sustainable food futures. New Zealand Sociology, 28(4), |23-145.

DuPuis, E. M., \& Goodman, D. (2005). Should we go "home" to eat?: Toward a reflexive politics of localism. Journal of Rural Studies, 2 I (3), 359-37I. http://doi.org/ 10.10 I6/j.jrurstud.2005.05.0I I

Goodman, D., DuPuis, M., \& Goodman, M. (20I2). Alternative food networks: Knowledge, practice, and politics. London, UK: Routledge.

Hinrichs, C. C. (20।4). Transitions to sustainability: A change in thinking about food systems change? Agriculture and Human Values, 31, | 43-155. http://doi.org/ | 0. I007/s 10460-014-9479-5

Lang,T., Millstone, E., Lewis, T., \& McFarlane, G. (2018). Why local authorities should prepare food Brexit plans. Retrieved from https:// foodresearch.org.uk/publications/local-authorities-food-brexit/

MacRae, R. J., \& Donahue, K. (2013). Municipal food policy entrepreneurs: A preliminary analysis of how Canadian cities and regional food districts are involved in food system change. Retrieved from http://tfpc.to/wordpress/wp-content/uploads/20 I3/05/ReportMay30-FINAL.pdf

Marsden, T. (2013). From post-productionism to reflexive governance: Contested transitions in securing more sustainable food futures. Journal of Rural Studies, 29, 123-134. https://doi.org/ / 0. 10 I 6/j.jrurstud.20 I 1. 10.001

Marsden, T., \& Franklin, A. (2013). Replacing neoliberalism: Theoretical implications of the rise of local food movements. Local Environment, / 8(5), 636-64I. https://doi.org/10.1080/I3549839.2013.797I57

Mason, P., \& Lang, T. (20 I 8). Sustainable diets. In P. Mason \& T. Lang, Sustainable diets: How ecological nutrition can transform consumption and the food system. New York, NY: Routledge. http://doi.org/ I 0.4324/978I $315802930-2$

Moragues-Faus, A., \& Morgan, K. (2015). Reframing the foodscape: The emergent world of urban food policy. Environment and Planning A, 47(7), 1558-1573. http://doi.org/10.1 177/03085 I 8X15595754

Morgan, K. (2014). Nourishing the city: The rise of the urban food question in the global North. Urban Studies, 52(8), I-I6. http:// doi.org/I 0.1 177/0042098014534902

Mougeot, L. J. A. (2006). Growing better cities: Urban agriculture for sustainable development. Ottawa, ON: International Development Research Centre.

Pollans, M., \& Roberts, M. (2014). Setting the table for urban agriculture. The Urban Lawyer, 46(2), 199-225.

Ross, J. (20 I7).'Place' is more than a physical location: A broader engagement of 'place' to further understand nursing practice. Scope: Contemporary Research Topics: Health and Wellbeing 2, I6-23.

Santo, R., \& Moragues-Faus, A. (2019). Towards a trans-local food governance: Exploring the transformative capacity of food policy assemblages in the US and UK. Geoforum, 98, 75-87. http://doi.org/10.1016/j.geoforum.2018.10.002

Sustainable Food Cities. (n.d.). Sustainable food cities network. Retrieved from http://sustainablefoodcities.org/ 